\title{
エレベータリングにおける交通需要の推定法と検定法
}

\author{
平 沢 宏太 郎 \\ （株）日立製作所日立研究所 日立市久慈町大甕 4026 \\ (昭和 46 年 5 月 11 日 受付)
}

\section{Estimation and Test of Traffic Demand of Elevatoring}

\author{
Kōtarō Hirasawa \\ (Hitachi Research Laboratory of Hitachi Ltd., Hitachi)
}

(Received May 11, 1971)

\begin{abstract}
Although the mean passenger arrival rate $\lambda_{i j}$ from $i$ th floor to $j$ th floor is the most important "data for an elevator traffic calculation, it can not be measured easily. Therefore a method to estimate $\lambda_{i j}$ from easily obtainable data has been in much demand.

In this thesis, two methods of $\lambda_{i j}$ estimation (for the time being, they are named the first method and the second method, respectively) and the test method of evaluating these methods statistically are presented.

The first method is suitable for a rough estimation and the second method is suitable for a detailed estimation.

The test method is based on the principle that the coincidence of the measured value and the estimated value of $\lambda_{i j}$ is not always optimum.

By the numerical study, it has been proved that those estimation methods are effective.
\end{abstract}

\section{1. まえがき}

$i$ 階から $j$ 階にいく目的で, 単位時間に $i$ 階に到着 する扮客の平均人数 $\lambda_{i j}($ 人/s) は, エレベータ交通計 算の基本となるデータであるが，実測が困難（特に超 高層ビルでは) なため，簡単に手にはいる資料から $\lambda_{i j}$ を推定する手法の開発が強く要求されていた. 本 論文では, 具体的な推定法として提案する 2 つの推定 法（かりに，第 1 推定法，第 2 推定法と名付ける）と， これらの推定法の良否を評価する検定理論についての ベる.

\section{2. $\lambda_{i j}$ 推 定 法}

Fig. 1 亿示すように, ビルの階床を昇り方向, 降 り方向の順に， $\underline{1}, \underline{2}, \cdots, \underline{F}, \cdots, \underline{2 F-2}$ のように番号づ 壮をする。ここで, 1 は最下階, $F$ は最上階である。 ホールという使い方は昇り, 降り方向を考慮した， $i$ 階といら使い方は昇り降り方向を一括した呼称と約束 する.したがって, 昇り方向については, $\underline{i}$ ホール

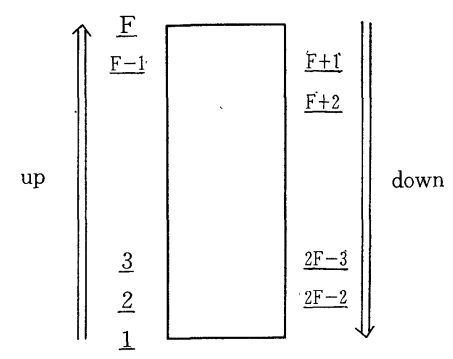

Fig. 1 Naming of building's floor

$i$ 階莽り方向, 降り方向については, $2 F-i$ ホール $=i$ 階降り方向となる. 第 1 推定法は非常に大まかな $\lambda_{i j}$ の推定に適した手法であり,

（1） 5 分間にエレベータを使用する客数はビル総 収容人口の何\%であるか (TD, traffic demand)

（2）基準階から出入りする交通需要の全交通需要 に占める割合 $\left(k_{1}=\right.$ 外部交通需要/全交通需要)

（3）基準階からビルにはいってくる交通需要の基 準階から出入りする交通需要に対する割合 $\left(k_{2}=\right.$ 外部 


\section{入力交通需要/外部交通需要）}

（4）ビル内部（基準階から出入りする交通需要を のぞく）の年り交通需要のビル内部の全交通需要に対 する割合 $\left(k_{3}=\right.$ 内部昇り交通需要/内部交通需要）

（5）各階の収容人口 $\left(y_{i}\right)$ ，ビルのテナント構成 を考虑して $\lambda_{i j}$ を推定する手法である．本手法は， $\mathrm{TD}, k_{1}, k_{2}, k_{3}$ などを変更することにより, 出勤，退 勤, 昼食, 平常, 閑散, 偏昇, 偏降1)などの $\lambda_{i j}$ を推 定することができる．第 2 推定法は，第 1 推定法より 良好な $\lambda_{i j}$ の推定を行な5目的で開発した手法であり，

（1）各ホール $(\underline{1}, \underline{2}, \cdots, \underline{2 F-2)}$ にエレベータに乗 ろうと思って単位時間に到着する招客の平均人数の実 測値 $\left(\lambda_{i}{ }^{\prime i n}\right)$

（2）単位時間に各ホールでエレベータから降りる 扮客の平均人数の実測值 $\left(\lambda_{\underline{i}}{ }^{\text {out }}\right)$

（3），各階の収容人口 $\left(y_{i}\right)$ ，ビルのテナント構成 を考慮して $\lambda_{i j}$ を推定する手法である．第 2 推定法は

(a) $\lambda_{\underline{i}}^{\text {'in }}, \lambda_{\underline{i}}^{\text {'out }}$ 加 $\mathrm{TD}, k_{1}, k_{2}, k_{3}$ を計算する.

（b）第1推定法によって，TD， $k_{1}, k_{2}, k_{3}$ などに より $\lambda_{i j}$ の推定を行なう.

(c) (b)の $\lambda_{i j}$ より求まる $\lambda_{\underline{i}}^{\text {in }}=\sum_{\underline{j}} \lambda_{\underline{i}}, \lambda_{\underline{i}}$ out $=$ $\sum_{j} \lambda_{\underline{j} i}$ と， $\lambda_{i}{ }^{\text {in }}, \lambda_{i}{ }^{\text {out }}$ ができるだけ一致し，しかも

（b）の $\lambda_{i j}$ の性質を保持するくりかえし形の修正計 “算を行なう.

より構成されている．第 2 推定法は，第 1 推定法より 多くの情報量を使用するといら意味で, 第 1 推定法よ り，精度の良い推定が可能であるが， $\lambda_{i}{ }^{\prime \text { in }} ， \lambda_{i}{ }^{\prime \text { out }}$ の 実測という問題がある。な特，上記（c）の修正計算 は，（b）で求まった $\lambda_{i j}$ の性質をできるだけ保持し ながら， $\lambda_{\underline{i}}{ }^{\text {in }}$ と $\lambda_{i}{ }^{\text {jn }}, \lambda_{\underline{i}}{ }^{\text {out }}$ と $\lambda_{\underline{i}}^{\text {out }}$ ができるだけ 一致するように $\lambda_{i j}$ を修正するといら道路交通の配合 問題などでよく知られている平均係数法, デトロイト 法，フレータ法2)を使用した。

\section{$2 \cdot 1$ 第 1 推定法}

入力データは, TD, $k_{1}, k_{2}, k_{3}, y_{i}, F:$ ビルの階床 数 (階), $k$ : 基準階 (階), $P: 1$ 階木交通需要係数 $(0 \sim 1), Q$ : 会社相互間交通需要係数 $(0 \sim 1), I_{i}, I_{i}$ : 会社相互間指標， $y$ : ビルの総收容人口である. 1 階 床交通需要係数 : $i \sim i+1$ 階間, もしくは $i \sim i-1$ 階 間の交通需要のその他の階間の交通需要に対する割合 $(0 \sim 1)$, 会社相互間交通需要俰数：異なる会社階間の 交通需要の同じ会社階間の交通需要に対する割合 $(0 \sim$ 1 ), 会社相互間指標： $i$ 階と $j$ 階が異なる会社のとき $I_{i} \neq I_{j}$.
第 1 推定法の基本的考方方は,

（1）外部交通需要は，各階の人口比で配分する

$$
\text { (たとえば， } \left.\lambda_{\underline{k} j}=y \times \frac{\mathrm{TD}}{100} \times \frac{1}{300} k_{1} k_{2} \frac{y_{j}}{y-y_{k}}\right)
$$

（2）内部交通需要は, テナント構成 $(P, Q)$, 各階 の収容人口 $\left(y_{i}\right)$ を考慮して構成された各ホール間の 第 2 配分係数 $\rho_{2 i j}=\rho_{1 i j} y_{i} y_{j}$ にて各階に配分する

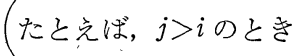

$$
\left.\lambda_{i j}=\frac{\rho_{2 i \underline{j}}}{\sum_{\underline{i}} \sum_{\underline{j}} \rho_{2 i \underline{j}}} y \times \frac{\mathrm{TD}}{100} \times \frac{1}{300}\left(1-k_{1}\right) k_{3}\right)
$$

（3）第 2 配分係数内の第 1 配分係数 $\rho_{1 i j}$ は,

$i$ と $j$ が異なる会社のとき $\quad \rho_{1 \underline{i} . j}=Q$

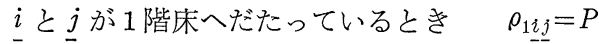

iと $j$ が異なる会社で，しかも1階床へだたってい るとき $\rho_{1 \underline{j} j}=M_{\mathrm{in}}(P, Q)$

である.

\section{$2 \cdot 2$ 第 2 推定法}

入力データは, $F, k, P, Q, I_{i}, y_{i}, N_{\max }$ : 平均係 数法, デトロイト法, フレータ法などの収束計算繰返 乙回数 (回), $\lambda_{\underline{1}}{ }^{\text {in }}$ : エレベータに乗ろらと思って単 位時間に $i$ ホールに到着する怙客の平均人数の実測値 (人/s), $\lambda_{\underline{i}}{ }^{\text {out }}$ : 単位時間に $i$ ホールでエレベータから 特りる扮客の平均人数の実測值 $($ 人 $/ \mathrm{s})$ である. 第 2 推定法は前述したと和り，（a） TD， $k_{1}, k_{2}, k_{3}$ の計 算，（b ）第 1 推定法，（c） $\lambda_{i j}$ の修正計算部分上り

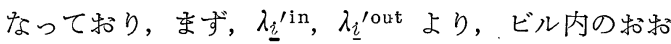
まかな交通の流れ（TD， $k_{1}, k_{2}, k_{3}$ ) をつかみ，これ を使って第 1 推定法より和扮まかな $\lambda_{i j}$ の推定を行な ら.その後, 第 1 推定法で計算された $\lambda_{i j}$ の性質をでき るだけたもちながら（祌のもつパターンをできるか ぎりいかしながら） $\lambda_{\underline{i}}^{\text {in }}$ と $\lambda_{\underline{i}}^{\text {in }}, \lambda_{\underline{i}}^{\text {'out }}$ と $\lambda_{\underline{i}}^{\text {out }}$ が できるだけ一致するような $\lambda_{i j}$ の修正計算を行なう手 法である.

(c) の修正計算 ${ }^{2}$ は,

(1) 平均係数法

$$
\lambda_{\underline{i} \underline{j}} \leftarrow \lambda_{\underline{i} \underline{j}}\left(\frac{\lambda_{\underline{i}}^{\text {'in }}}{\lambda_{\underline{i}}^{\text {in }}}+\frac{\lambda_{\underline{j}^{\prime}}^{\text {out }}}{\lambda_{\underline{j}}^{\text {out }}}\right) / 2
$$

（ロ） デトロイト法

$$
\lambda_{i j} \leftarrow \lambda_{i j} \frac{\lambda_{\underline{i}}{ }^{\text {in }} \lambda_{\underline{j}}{ }^{\text {out }} \lambda}{\lambda_{\underline{i}}^{\text {in } \lambda_{\underline{j}} \text { out } \lambda^{\prime}}}
$$

ここで,

$$
\begin{array}{ll}
\lambda_{\underline{i}}^{\text {in }}=\sum_{\underline{j}} \lambda_{\underline{i}}, & \lambda_{\underline{i}}{ }^{\text {out }}=\sum_{\underline{j}} \lambda_{\underline{j i}} \\
\lambda^{\prime}=\sum_{\underline{i}} \lambda_{\underline{i}}^{\text {in }}, \quad \lambda=\sum_{\underline{i}} \lambda_{\underline{i}}^{\text {in }}
\end{array}
$$




$$
\begin{aligned}
& \text { (八) フレータ法 } \\
& \lambda_{\underline{i} \underline{j}} \leftarrow \lambda_{\underline{i} \underline{j}}\left(\frac{\lambda_{\underline{i}}^{\text {in }} \lambda_{j}{ }^{\text {out }}}{\beta(i) \underline{\lambda}_{\underline{j}}^{\text {out }}}+\frac{\lambda_{\underline{j}}^{\text {out }}}{\alpha(j)} \frac{\lambda_{\underline{\underline{i}}}^{\text {in }}}{\lambda_{\underline{i n}}^{\text {in }}}\right) / 2
\end{aligned}
$$

ここで,

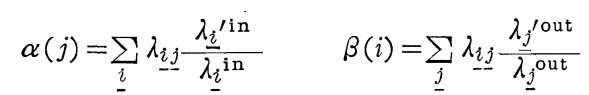

の交通配分の問題でよく知られた手法を使用した.

\section{3. $\lambda_{i j}$ の検 定 法}

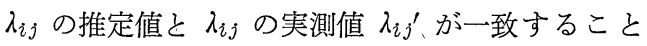
がかならずしも最適な $\lambda_{i j}$ の推定法でないということ 飞着目し，推定法の良否を統計的な観点から評価する 方法, 寸なわち, $\lambda_{i j}{ }^{\prime}$ から $\lambda_{i j}$ の真の值の分布を計算 し，この分布を使用して，95\%の信頼度で真值が存在 する区間を求め，この信頼区間の中に $\lambda_{i j}$ の推定值 が全体の何\%はいっているかによって推定法の良否 を評価する手法を確立した。

\section{$3 \cdot 1 f_{n, T}(\lambda)$ の計算法}

本節では $T$ 秒間に $n$ 人実測した場合の $\lambda$ の真の值 ( $\lambda_{i j}$ を簡単のため $\lambda$ と記す) の確率密度関数 $f_{n, T}(\lambda)$ を計算する。文献 3 によると, 敃客の到着時間間隔の 分布がポアンン, アーラン, 集団分布に従って, $T$ 秒 間に $n$ 人の怙客がホールに到着する確率 $P_{n, T}(\lambda)$ は,

case 1） ポアソン分布のとき，

$$
P_{n, T}(\lambda)=\frac{(\lambda T)^{n} e^{-\lambda T}}{n !}
$$

ここで, $\lambda:$ 乗客の平均到着率

case 2) 位相 $k^{\prime}$ のアーラン分布のとき,

$$
\begin{gathered}
P_{n, T}(\lambda)=\frac{1}{k^{\prime}}\left[\sum_{i=k^{\prime} n}^{(n+1) k^{\prime}-1}\left(k^{\prime}+k^{\prime} n-i\right) \frac{\left(k^{\prime} \lambda T\right)^{i} e^{-k^{\prime} \lambda T}}{i !}\right. \\
+\sum_{i=(n-1) k^{\prime}+1}^{k^{\prime} n-1}\left(k^{\prime}-k^{\prime} n+i\right) \frac{\left(k^{\prime} \lambda T\right)^{i} e^{-k^{\prime} \lambda T}}{i !} \\
P_{0, T}(\lambda)=\frac{1}{k^{\prime}} \sum_{i=0}^{k^{\prime}-1}\left(k^{\prime}-i\right) \frac{\left(k^{\prime} \lambda T\right)^{i} e^{-k^{\prime} \lambda T}}{i !}
\end{gathered}
$$

case 3）集団分布のとき，

$$
P_{n, T}(\lambda)=\sum_{i=0}^{\infty} e^{-\left(\lambda / \lambda^{\prime \prime}\right) T} \frac{\left(\frac{\lambda}{\lambda^{\prime \prime}} T\right)^{i}}{i !} \frac{\left(i \lambda^{\prime \prime}\right)^{n} e^{-i \lambda^{\prime \prime}}}{n !}
$$

ここで， $\lambda^{\prime \prime}$ ：集団の平均人数（集団間の到着間隔の 分布関数は指数分布, 集団内の人数をポアソン分布と する).

となる、したがって， $T$ 秒間に $n$ 人実測した場合の $\lambda$ の真の値の確率密度関数 $f_{n, T}(\lambda)$ は,

$$
f_{n, T}(\lambda)=\frac{P_{n, T}(\lambda)}{\int_{0}^{\infty} P_{n, T}(\lambda) d \lambda}
$$

に（4)〜（7）式を代入して，

case 1) ポアソン分布のとき，

$$
f_{n, T}(\lambda)=T \frac{(\lambda T)^{n} e^{-\lambda T}}{n !}
$$

case 2) 位相 $k^{\prime}$ のアーラン分布のとき，

$$
\begin{gathered}
f_{n, T}(\lambda)=\left\{\frac { 1 } { k ^ { \prime } } \left[\sum_{i=k^{\prime} n}^{(n+1) k^{\prime}-1}\left(k^{\prime}+k^{\prime} n-i\right) \frac{\left(k^{\prime} \lambda T\right)^{i} e^{-k^{\prime} \lambda T}}{i !}\right.\right. \\
\left.\left.+\sum_{i=(n-1) k^{\prime}+1}^{k^{\prime} n-1}\left(k^{\prime}-k^{\prime} n+i\right) \frac{\left(k^{\prime} \lambda T\right)^{i} e^{-k^{\prime} \lambda T}}{i !}\right]\right\} / B \\
B=\sum_{i=k^{\prime} n}^{(n+1) k^{\prime}-1}\left(k^{\prime}+k^{\prime} n-i\right) \frac{1}{k^{\prime 2} T} \\
+\sum_{i=(n-1) k^{\prime}+1}^{k^{\prime} n-1}\left(k^{\prime}-k^{\prime} n+i\right) \frac{1}{k^{\prime 2} T} \quad n=1,2, \cdots \\
f_{0, T}(\lambda)=\frac{\sum_{i=0}^{k^{\prime}-1}\left(k^{\prime}-i\right) \frac{\left(k^{\prime} \lambda T\right)^{i} e^{-k^{\prime} \lambda T}}{i !}}{\sum_{i=0}^{k^{\prime}-1}\left(k^{\prime}-i\right) \frac{1}{k^{\prime} T}}
\end{gathered}
$$

case 3) 集団分布のとき，

$$
f_{n, T}(\lambda)=\frac{\sum_{i=0}^{\infty} e^{-\left(\lambda / \lambda^{\prime \prime}\right) T} \frac{\left(\frac{\lambda}{\lambda^{\prime \prime}} T\right)^{i}}{i !} \frac{\left(i \lambda^{\prime \prime}\right)^{n} e^{-i \lambda^{\prime \prime}}}{n !}}{\sum_{i=0}^{\infty} \frac{\left(i \lambda^{\prime \prime}\right)^{n} e^{-i \lambda^{\prime \prime}}}{n !} \frac{\lambda^{\prime \prime}}{T}}
$$

となる。

\section{$3 \cdot 2 \underline{\lambda}_{n, T} \boldsymbol{T} \sim \bar{\lambda}_{n, T} \boldsymbol{T}$ の計算法}

(9) (12) 式の $f_{n, T}(\lambda)$ を使用して,

$$
\begin{aligned}
& \int_{0}^{\lambda_{i} j} f_{n, T}(\lambda) d \lambda=0.025 \\
& \int_{\bar{\lambda}_{i j}}^{\infty} f_{n, T}(\lambda) d \lambda=0.025
\end{aligned}
$$

となる. $\underline{\lambda}_{i j}, \bar{\lambda}_{i j}$ を求めると， $\lambda_{i j}$ の真の值が $95 \%$ の 信頼度で $\lambda_{i j} \sim \bar{\lambda}_{i j}$ の範囲にあるといらことができる. したがって,

この $95 \%$ 信頼区間の中に, $\lambda_{i j}$ の推定值が全体 ( $F^{2}-F$ 個) の何\%はいっているか (95\% 信頼度推 定率と名付注こととする）によって推定法の良否を 評価するものとした.

(9) （12）式の $f_{n, T}(\lambda)$ の中には, 実測時間 $T$ は, すべて $T\left((\beta \lambda T)^{n} e^{-\beta \lambda T} / n !\right)$ の形で含まれている. い っぽう，任意の值 $S$ にいて，

$$
\int_{0}^{s} T \frac{(\beta \lambda T)^{n} e^{-\beta \lambda T}}{n !} d \lambda
$$

を計算すると，

$$
\int_{0}^{s} T \frac{(\beta \lambda T)^{n} e^{-\beta \lambda T}}{n !} d \lambda=\frac{1}{\beta}\left[1-e^{-\beta T S} \sum_{k=0}^{n} \frac{(\beta T S)^{k}}{k !}\right]
$$

となるため $T$ 秒間に $n$ 人のお客の到着を実測したとき 
の $95 \%$ 信頼区間 $\underline{\lambda}_{n, T} \sim \bar{\lambda}_{n, T}$ は, $\alpha T$ 秒 間に $n$ 人実測したときの $95 \%$ 信頼区間の 特の特の $\alpha$ 倍となる．換言すると $\underline{\lambda}_{n, T} T$ $\bar{\lambda}_{n, T} T$ は，Tの值依存せず一定となる。 したがって具体的な $95 \%$ 信頼度推定率の 計算は，乗客の実測人数が $\underline{\lambda}_{n, T} T \sim \bar{\lambda}_{n, T} T$ の中にどの程度 (全体の何\%) はいってい るかによって計算することとした．

\section{4. 数値解析結果}

本章では, 2., 3. で論じた理論の数值検 討結果についてのべる。

\section{$4 \cdot 1 \lambda_{n, T} T \sim \bar{\lambda}_{n, T} T$ の数值計算}

Table 1 飞, 扮客の到着の実測数 $n$ を 0 8 とか光 たときの $\lambda_{n, T} T, \bar{\lambda}_{n, T} T$ を和客の到着時間間隔の分布 を集団到着，ポアソン到着，アーラン到着とした場合 について記す。 ここで，集団の平均人数を $\lambda^{\prime \prime}=2$ 人， アーラン到着の位相数を $k^{\prime}=2$ とした. これから，

（1）和客の到着時間間隔の分布が，アーラン到着, ポアソン到着，集団到着となるほど 95\% 信頼区間 $\underline{\lambda}_{n, T} T \sim \bar{\lambda}_{n, T} T$ は大きくなる，換言すると，集団到着 に近いほど，真の招客の平均到着率が実測值からはず れる可能性が大きくなる.

などがわかる。
Table 1 Table of $\underline{\lambda}_{n, T} T, \bar{\lambda}_{n, T} T$

\begin{tabular}{c|c|c|c|c|c|c}
\hline \multicolumn{2}{c|}{ bulk passenger arrival } & \multicolumn{2}{c|}{$\begin{array}{c}\text { poisson passenger } \\
\text { arrival }\end{array}$} & \multicolumn{2}{c}{$\begin{array}{c}\text { erlang passenger } \\
\text { arrival }\end{array}$} \\
\hline$n(p)$ & $\underline{\lambda}_{n, T} T(p)$ & $\bar{\lambda}_{n, T} T(p)$ & $\underline{\lambda}_{n, T} T(p)$ & $\bar{\lambda}_{n, T} T(p)$ & $\underline{\lambda}_{n, T} T(p)$ & $\bar{\lambda}_{n, T} T(p)$ \\
\hline 0 & 0.07 & 8.51 & 0.03 & 3.68 & 0.02 & 2.31 \\
1 & 0.60 & 12.86 & 0.26 & 5.56 & 0.24 & 3.78 \\
2 & 0.67 & 14.19 & 0.63 & 7.20 & 0.75 & 5.23 \\
3 & 0.84 & 15.82 & 1.12 & 8.76 & 1.37 & 6.62 \\
4 & 1.12 & 17.58 & 1.65 & 10.20 & 2.03 & 7.97 \\
5 & 1.44 & 19.27 & 2.22 & 11.64 & 2.70 & 9.24 \\
6 & 1.89 & 20.88 & 2.87 & 13.02 & 3.45 & 10.53 \\
7 & 2.30 & 22.49 & 3.52 & 14.40 & 4.20 & 11.78 \\
8 & 2.75 & 23.95 & 4.14 & 15.75 & 4.93 & 13.01 \\
\hline \multicolumn{7}{l}{} \\
\hline
\end{tabular}

\section{$4 \cdot 2$ 実測デー夕}

$\lambda_{i j}$ の推定法の検討を行ならためのデータとして, 東京某ビル，実測した 4 ケースの $\lambda_{i j}$ を使用した。 case 1 (Table 2 参照) $T=25200 \mathrm{~s}, \mathrm{TD}=3.24 \%$ ，

$$
k_{1}=0.5008, k_{2}=0.5173, k_{3}=0.5560
$$

case $2 T=25200 \mathrm{~s}, \mathrm{TD}=3.349 \%, \quad k_{1}=0.5015$, $k_{2}=0.5341, k_{3}=0.5661$

case $3 T=4200 \mathrm{~s}, \mathrm{TD}=4.605 \%, k_{1}=0.5050$, $k_{2}=0.5162, \quad k_{3}=0.6325$

case $4 T=10200 \mathrm{~s}, \mathrm{TD}=2.767 \%, k_{1}=0.5281$, $k_{2}=0.5724, \quad k_{3}=0.5714$

Table 3 に，某ビルのテナント構成を示す，表中， $y_{i}$ は各階の収容人口， $I_{i}$ は会社相互間指標であり，

Table 2 Measured data $\lambda_{i j}{ }^{\prime} T$ case 1

\begin{tabular}{|c|c|c|c|c|c|c|c|c|c|c|c|c|c|c|}
\hline$i_{i}^{j}$ & 1 & 2 & 3 & 4 & 5 & 6 & 7 & 8 & 9 & 10 & 11 & 12 & 13 & 14 \\
\hline 1 & & 3 & 36 & 15 & 5 & 5 & 2 & 4 & 2 & 2 & -0 & 6 & 9 & 2 \\
\hline 2 & 1. & & 8 & 37 & 36 & 25 & 22 & 22 & 15 & 11 & 12 & 25 & 22 & 3 \\
\hline 3 & 3 & 5 & & 21 & 28 & 100 & 78 & 56 & 65 & 58 & 67 & 57 & 102 & 11 \\
\hline 4 & 9 & 9 & 10 & & 13 & 113 & 203 & 104 & 253 & 170 & 182 & 114 & 143 & 11 \\
\hline 5 & 1 & 26 & 20 & 8 & & 11 & 12 & 65 & 73 & 0 & 0 & 2 & 46 & 7 \\
\hline 6 & 5 & 27 & 80 & 85 & 3 & & 12 & 23 & 53 & 3 & 4 & 4 & 21 & 9 \\
\hline 7 & 0 & 13 & 56 & 147 & 7 & 0 & & 11 & 10 & 5 & 15 & 7 & 30 & 2 \\
\hline 8 & 3 & 18 & 44 & 109 & 42 & 15 & 0 & & 6 & 1 & 2 & 6 & 20 & 1 \\
\hline 9 & 0 & 18 & 75 & 210 & 71 & 33 & 8 & 2 & & 0 & 2 & 2 & 16 & 1 \\
\hline 10 & 0 & 4 & 48 & 176 & 0 & 5 & 5 & 2 & 0 & & 4 & 30 & 9 & 1 \\
\hline 11 & 0 & 10 & 45 & 205 & 0 & 5 & 19 & 1 & 7 & 0 & & 0 & 0 & 0 \\
\hline 12 & 4 & 27 & 37 & 102 & 1 & 2 & 13 & 9 & 0 & 17 & 1 & & 0 & 0 \\
\hline 13 & 0 & 28 & 91 & 121 & 56 & 26 & 23 & 27 & 20 & 4 & 3 & 0 & & 5 \\
\hline 14 & 3 & 2 & 3 & 9 & 5 & 3 & 5 & 1 & 0 & 4 & 0 & 0 & 0 & \\
\hline
\end{tabular}

Table 3 Tenant form

\begin{tabular}{r|r|r|r|r|r|r|r|r|r|r|r|r|r|r|r}
\hline & 14 & 13 & 12 & 11 & 10 & 9 & 8 & 7 & 6 & 5 & 4 & 3 & 2 & 1 & total \\
\hline$y_{i}$ & 4 & 117 & 134 & 172 & 205 & 197 & 116 & 265 & 226 & 199 & 66 & 134 & 45 & 12 & 1892 \\
$I_{i}$ & 8 & 7 & 6 & 6 & 5 & 4 & 4 & 4 & 4 & 4 & 4 & 3 & 2 & 1 & \\
\hline
\end{tabular}


$i$ 階と $j$ 階が異なる会社のとき $I_{i} \neq I_{j}$ となる.

\section{$4 \cdot 3$ 第 2 推定法における収束速度の検討}

ここでは, 第 2 推定法に括ける $\lambda_{\underline{i}}{ }^{\text {in }}$ と $\lambda_{\underline{i}}{ }^{\text {in }}, \lambda_{\underline{i}}{ }^{\text {'out }}$

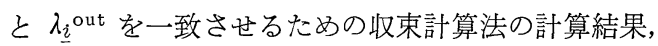
特に, 平均係数法, デトロイト法, フレータ法の收束 法の差異について論ずる. Fig. 2〜 Fig. 5 亿 case 1 〜 case 4 のデータにつき, 平均係数法, デトロイト 法, フレータ法の各収束法の $95 \%$ 信頼度推定率計算 結果を示す. 図中の $P, Q$ の值は，和の抢のケースで 最適と思われる $(4.4$ に示すと特り， $P, Q$ による差 は注とんどないのであるが) 值を使用し，拈客の到着

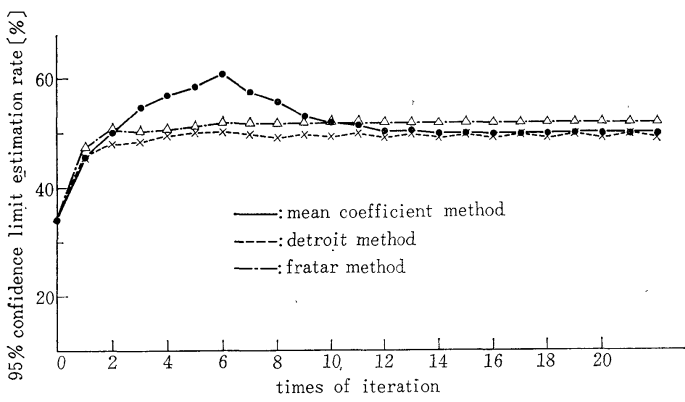

Fig. 2 Convergence state of $95 \%$ confidence limit estimation rate (case 1 )

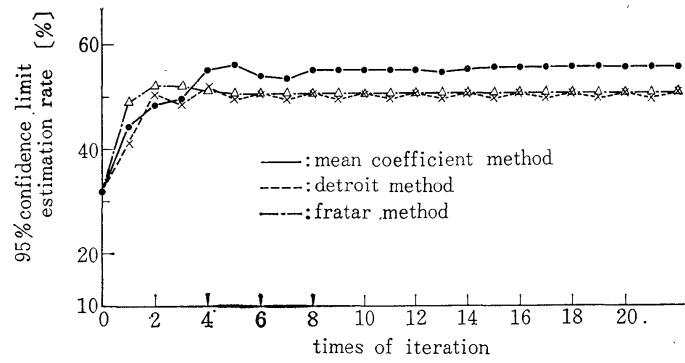

Fig. 3 Convergence state of $95 \%$ confidence limit estimation rate (case 2)

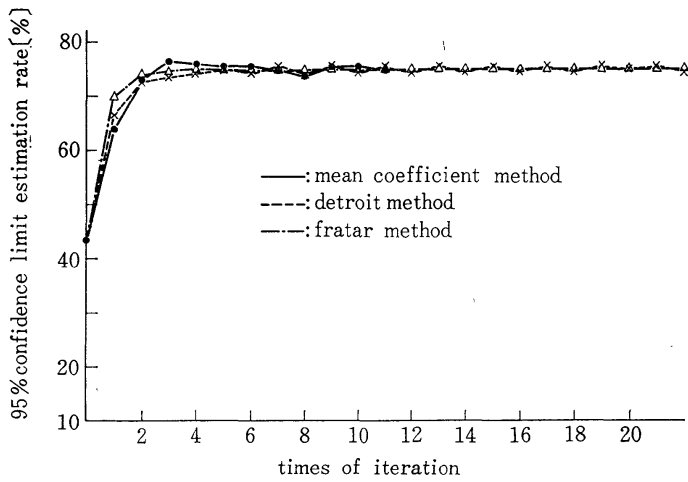

Fig. 4 Convergence state of $95 \%$ confidence limit estimation rate (case 3 )

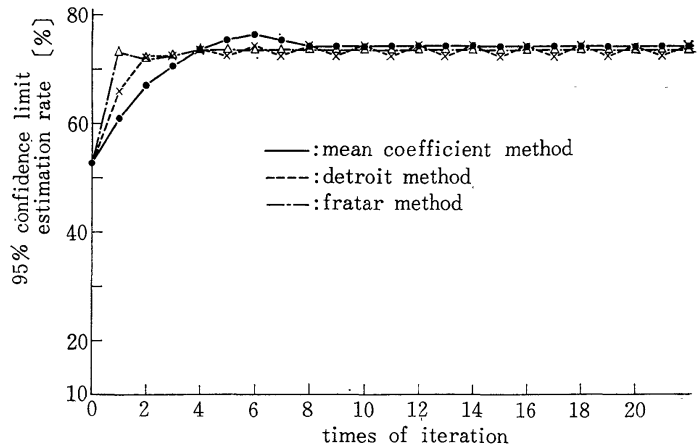

Fig. 5 Convergence state of $95 \%$ confidence limit estimation rate (case 4)

時間間隔の分布をポアソン分布とした．な特，繰返し 回数 0 とは，第 1 推定法の計算結果であることに注意 されたい.これから，

（1）わずかな差ではあるが，フレータ法による収 束計算が一番少ない繰返し回数で収束する。

（2）デトロイト法は，十分な繰返し計算を行なっ たあとでる，わずかながらハンチングを和こす。

（3）収束計算の途上で，95\% 信頼度推定率が最 大となる場合がある。このことは，実測データ $\lambda_{\underline{i}}^{\prime i n}$ ， $\lambda_{\underline{i}}^{\text {out }}$ と推定值 $\lambda_{i}^{\text {in }}, \lambda_{i}$ out って推定が良好となることを示している。 などがわかる。

\section{$4.4 P, Q$ の影響}

Table 4 Table 6 飞 case 1〜 case 4 のデータに つき，P，Qを0.1，0.5，1.0 とか元て計算した結果 を示す. 4.3 と同様，捻客の到着時間間隔の分布をポ アソン分布として 95\% 信頼度推定率を計算した。 Table 4 は第 1 推定法の, Table 5, Table, 6 は第 2 推定法の計算結果, 特に Table 5 は平均係数法によ る収束後の值 (したがって $\lambda_{i}{ }^{\prime \text { in }}=\lambda_{i}{ }^{\text {in }}, \lambda_{i}{ }^{\prime \text { out }}=\lambda_{i}{ }^{\text {out }}$ ), Table 6 は平均係数法の収束計算途上で，95\% 信頼 度推定率が最大となった值である。これから，

（1） $P, Q$ の值は，推定法の良否に注とんぞ影響 を扣よぼさない。

（2）第 2 推定法が第 1 推定法より推定精度が良好 である（第1 推定法より多くの情報を入力するので当 然の結果とい方る)

（3）第 2 推定法では，収束計算の途上で，95\% 信頼度推定率が最大となる場合がある. などがわかる。

\section{5. む す び}

以上，各ビルの特徴をとらえた簡単に手にはいる資 
Table 4 Confidence limit estimation rate- $P, Q$ parameter

\begin{tabular}{|c|c|c|c|c|c|c|c|c|c|}
\hline \multicolumn{5}{|c|}{ case 1} & \multicolumn{5}{|c|}{ case $3 \quad(T=4200 \mathrm{~s})$} \\
\hline \multirow{2}{*}{\multicolumn{2}{|c|}{$\begin{aligned} \mathrm{TD}=3.24 \% \\
k_{1}=0.5008 \\
k_{2}=0.5173 \\
k_{3}=0.5560\end{aligned}$}} & \multicolumn{3}{|c|}{$Q$} & \multirow{2}{*}{\multicolumn{2}{|c|}{$\begin{aligned} \mathrm{TD} & =4.605 \% \\
k_{1} & =0.5050 \\
k_{2} & =0.5162 \\
k_{3} & =0.6325\end{aligned}$}} & \multicolumn{3}{|c|}{$Q$} \\
\hline & & 0.1 & 0.5 & 1.0 & & & 0.1 & 0.5 & 1.0 \\
\hline \multirow{3}{*}{$P$} & 0.1 & 21.43 & 31.87 & 34.07 & \multirow{3}{*}{$P$} & 0.1 & 49.45 & 44.51 & 44.51 \\
\hline & 0.5 & 20.88 & 25.27 & 31.32 & & 0.5 & 44.51 & 42.31 & 43.41 \\
\hline & 1.0 & 23.64 & 24.73 & 29.12 & & 1.0 & 43.41 & 40.66 & 40.66 \\
\hline \multicolumn{5}{|c|}{ case 2} & \multicolumn{5}{|c|}{ case $4 \quad(T=10200 \mathrm{~s})$} \\
\hline \multirow{2}{*}{\multicolumn{2}{|c|}{$\begin{array}{l}\mathrm{TD}=3.349 \% \\
k_{1}=0.5015 \\
k_{2}=0.5341 \\
k_{3}=0.5661\end{array}$}} & \multicolumn{3}{|c|}{$Q$} & \multirow{2}{*}{\multicolumn{2}{|c|}{$\begin{array}{l}\mathrm{TD}=2.767 \% \\
k_{1}=0.5281 \\
k_{2}=0.5724 \\
k_{3}=0.5714\end{array}$}} & \multicolumn{3}{|c|}{$Q$} \\
\hline & & 0.1 & 0.5 & 1.0 & & & 0.1 & 0.5 & 1.0 \\
\hline \multirow{3}{*}{$P$} & 0.1 & 27. 47 & 31.87 & 34.62 & \multirow{3}{*}{$P$} & 0.1 & 53.30 & $52.75^{\prime}$ & 48.90 \\
\hline & 0.5 & 26.37 & 27.47 & 26.92 & & 0.5 & 45.60 & 47.80 & 50.00 \\
\hline & 1.0 & 25.27 & 26.92 & 26.37 & & 1.0 & 46.15 & 46.15 & 48.35 \\
\hline
\end{tabular}

the first estimation method

Table 5 Confidence limit estimation rate- $P, Q$ parameter

\begin{tabular}{|c|c|c|c|c|c|c|c|c|c|}
\hline \multicolumn{5}{|c|}{$(T=25200 \mathrm{~s})$} & \multicolumn{5}{|c|}{ case $3 \quad(T=4200 \mathrm{~s})$} \\
\hline \multirow{2}{*}{\multicolumn{2}{|c|}{$\begin{array}{l}\mathrm{TD}=3.24 \% \\
k_{1}=0.5008 \\
k_{2}=0.5173 \\
k_{3}=0.5560\end{array}$}} & \multicolumn{3}{|c|}{$Q$} & \multirow{2}{*}{\multicolumn{2}{|c|}{$\begin{array}{l}\mathrm{TD}=4.605 \% \\
k_{1}=0.5050 \\
k_{2}=0.5162 \\
k_{3}=0.6325\end{array}$}} & \multicolumn{3}{|c|}{$Q$} \\
\hline & & 0.1 & 0.5 & 1.0 & & & 0.1 & 0.5 & 1.0 \\
\hline \multirow{3}{*}{$P$} & 0.1 & 48.90 & 47.25 & 49.45 & \multirow{3}{*}{$P$} & 0.1 & 71.98 & 74.18 & 71.43 \\
\hline & 0.5 & 47. 80 & 46.15 & 51.10 & & 0.5 & 70.33 & 74.73 & 75.27 \\
\hline & 1.0 & 45.05 & 44.51 & 46.15 & & 1.0 & 69.23 & 75.27 & 73. 63 \\
\hline \multicolumn{5}{|c|}{ case 2} & \multicolumn{5}{|c|}{ case $4 \quad(T=10200 \mathrm{~s})$} \\
\hline \multirow{2}{*}{\multicolumn{2}{|c|}{$\begin{aligned} \mathrm{TD} & =3.34 \% \\
k_{1} & =0.5015 \\
k_{2} & =0.5341 \\
k_{3} & =0.5661\end{aligned}$}} & \multicolumn{3}{|c|}{$Q$} & \multirow{2}{*}{\multicolumn{2}{|c|}{$\begin{array}{l}\mathrm{TD}=2.767 \% \\
k_{1}=0.5281 \\
k_{2}=0.5724 \\
k_{3}=0.5714\end{array}$}} & & $Q$ & \\
\hline & & 0.1 & 0.5 & 1.0 & & & $0: 1$ & 0.5 & 1.0 \\
\hline \multirow{3}{*}{$P$} & 0.1 & 52.20 & 55.49 & 52.75 & \multirow{3}{*}{$P$} & 0.1 & 69.23 & 74.18 & 70.33 \\
\hline & 0.5 & 50.55 & 52.75 & 54.95 & & 0.5 & 70.33 & 71.98 & 73.63 \\
\hline & 1.0 & 49.45 & 50.00 & 51.10 & & 1.0 & 68.68 & 69.78 & 72.53 \\
\hline
\end{tabular}

the second estimation method (after convergence)

料から $\lambda_{i j}$ を推定する手法として,

（1）第 1 推定法と名付杅る TD, $k_{1}, k_{2}, k_{3}, y_{i}$ およびテナント構成から $\lambda_{i j}$ を推定するやや大まかな 手法

（2）第 2 推定法と名付ける $\lambda_{i}{ }^{\text {in }} ， \lambda_{i}{ }^{\text {out }}, y_{i}$ 掠よ びテナント構成から $\lambda_{i j}$ を推定する精度の良好な手法

（3）さらに，これら推定法の良否を統計的な観点 から評価する手法

の開発を行なった。これらの理論, 数値検討から,

（1）拈客の到着時間間隔の分布がアーラン到着, ポアソン到着，集団到着になるほど，95\% 信頼区間 $\underline{\lambda}_{n, T} T \sim \bar{\lambda}_{n, T} T$ は大きくなる
（2）第 1, 第 2 推定法とも, 統計的観点から評価 してほぼ満足しえる推定法である

（3）第 2 推定法が第 1 推定法より推定精度が良好 である

（4） $P, Q$ の值は，推定法の良否汇とんぞ影響 を特よぼさない

（5）第 2 推定法では, 収束計算の途上で, $95 \%$ 信 頼度推定率が最大となる場合がある

（6）第 2 推定法の収束計算では, フレータ法の $95 \%$ 信頼度推定率の収束速度が一番早い

（7）第 2 推定法の収束計算に和䏠るデトロイト法 では，十分な繰返し計算を行なったあとでも，95\%信 
Table 6 Confidence limit estimation rate- $P, Q$ parameter

\begin{tabular}{|c|c|c|c|c|c|c|c|c|c|}
\hline \multicolumn{5}{|c|}{$(T=25200 \mathrm{~s})$} & \multicolumn{5}{|c|}{$(T=4200 \mathrm{~s})$} \\
\hline \multirow{2}{*}{\multicolumn{2}{|c|}{$\begin{array}{l}\mathrm{TD}=3.24 \% \\
k_{1}=0.5008 \\
k_{2}=0.5173 \\
k_{3}=0.5560\end{array}$}} & \multicolumn{3}{|c|}{$Q$} & \multirow{2}{*}{\multicolumn{2}{|c|}{$\begin{aligned} \mathrm{TD} & =4.605 \% \\
k_{1} & =0.5050 \\
k_{2} & =0.5162 \\
k_{3} & =0.6325\end{aligned}$}} & \multicolumn{3}{|c|}{$Q$} \\
\hline & & 0.1 & 0.5 & 1.0 & & & 0.1 & 0.5 & 1.0 \\
\hline \multirow{3}{*}{$P$} & 0.1 & 51.10 & 58.79 & 60.44 & \multirow{3}{*}{$P$} & 0.1 & 73.08 & 74.18 & 73.63 \\
\hline & 0.5 & 50.55 & 54.40 & 56.04 & & 0.5 & 71.98 & 74.73 & 76.37 \\
\hline & 1.0 & 50.00 & 50.55 & 53.85 & & 1.0 & 69.78 & 75.27 & 75.27 \\
\hline \multicolumn{5}{|c|}{ case 2} & \multicolumn{5}{|c|}{ case $4 \quad(T=10200 \mathrm{~s})$} \\
\hline \multirow{2}{*}{\multicolumn{2}{|c|}{$\begin{aligned} \mathrm{TD} & =3.349 \% \\
k_{1} & =0.5015 \\
k_{2} & =0.5341 \\
k_{3} & =0.5661\end{aligned}$}} & \multicolumn{3}{|c|}{$Q$} & \multirow{2}{*}{\multicolumn{2}{|c|}{$\begin{aligned} \mathrm{TD}=2.767 \% \\
k_{1}=0.5281 \\
k_{2}=0.5724 \\
k_{3}=0.5714\end{aligned}$}} & \multicolumn{3}{|c|}{$Q$} \\
\hline & & 0.1 & 0.5 & 1.0 & & & 0.1 & 0.5 & 1.0 \\
\hline \multirow{3}{*}{$P$} & 0.1 & 53.30 & 56.04 & 55.49 & \multirow{3}{*}{$P$} & 0.1 & 71.43 & 76.37 & 71.98 \\
\hline & 0.5 & 52.20 & 53.30 & 55.49 & & 0.5 & 70.33 & 73.63 & 73.63 \\
\hline & 1.0 & 50.55 & 52.20 & 51.10 & & 1.0 & 69.78 & 70.88 & 73.63 \\
\hline
\end{tabular}

the second estimation method (max volue)

頼度推定率にわずかなハンチング現象が生ずる などがあきらかとなった。

最後に,つねひごろ御指導いただいている当所前川 部長, 河竹部長, 川本室長, 水戸工場犬塚部長, 渡辺 主任技師，弓仲主任技師，岩坂技師に深謝します.
参 考 文 献

1）平沢 · 河竹 · 弓仲 · 岩坂 : 電学誌, 90, 1568 (昭 458)

2）横山：輸送，運搬にお㹁る OR 技法，91，培風館（昭 39-10)

3）平沢 : 電学誌, 91,299 (昭 46-2) 